within a random structure is difficult to define; however, the idea is that the electronic properties of the ideal structure would be similar to that of the corresponding crystal (if one exists). Thus, the defect, in this sense, is important in determining the specific electronic properties of the amorphous semiconductor. This is a rather extreme point of view for the structure of glass, in my opinion, yet the authors are able to cast much of the data within this framework. It is fair to point out, however, that models do exist which minimize the effect of local structural inhomogeneities but do enjoy similar success in explaining much of the data. These theories invoke a strong lattice interaction and, indeed, Mott and Davis discuss the simple negative- $U$ model first introduced by Anderson but narrowly interpreted here. Thus, the basic electronic structure for glassy semiconductors is not universally agreed.

The reviewer with the broad view may dismiss much of the current controversy as detail and indeed it is somewhat inconsequential when the contribution is taken as a whole. It is certainly true that some of the analysis given in this book will be finally shown to be incorrect. This is the risk the authors boldly took in attempting to characterize and define a new branch of solid state physics. It is fitting that the Nobel Prize in physics was awarded to Sir Nevill Mott for contributions to this field, many of which are included in this book.

D.C. Licciardello is an Assistant Professor of Physics at Princeton University, Princeton, New Jersey.

\section{Heavy stone circles}

\section{R.J.C. Atkinson}

Rings of Stone: The Prehistoric Stone Circles of Britain and Ireland. By Aubrey Burl, with photographs by Edward Piper. Pp.280. (Frances Lincoln/Weidenfeld and Nicolson: London, UK, 1979.) $£ 9.95$.

AUbrey BURL'S position as the leading authority on stone circles was established by the publication of his Stone Circles of the British Isles (Yale University Press, 1976), a work for scholars which is not likely to be superseded within the present century. Rings of Stone is a companion volume for the layman, extensively and admirably illustrated, but unencumbered by the apparatus criticus of scholarship. There is a glossary, a reading-list confined to books and monographs, and an index. The reader who is stimulated to seek primary sources must consult the bibliography and gazetteer of his earlier book.

Apart from its weight $(1.2 \mathrm{~kg})$ and its 27 colour plates on art paper, which are at the mercy of the fine soft rain which falls so frequently on stone circles, this is an excellent vade-mecum for the holiday traveller with a purpose, whether it be specifically archaeological or aesthetic. The amateur prehistorian will find it useful in guiding him to the best-preserved and most easily visited sites. The traveller bent, in the Romantic tradition, upon viewing these rugged and enigmatic works of man against their landscape background will be well served also, provided that he remembers that the rocky and treeless terrains which now surround many stone circles are themselves the product of man (and indeed of the builders of the circles themselves), and not of nature alone.

Readers with either purpose will be guided in their travels by the latter twothirds of this book, which describes and illustrates fifty stone circles in Britain and Ireland which are well preserved and easily visited. For each region there is a map showing the sites and the main roads. For each site there is a map reference and a plan and photographs, as well as a textual description which will delight the reader by its aptness and sensitivity, either from his prior knowledge of the monument or after his first visit. It is a pity, however, that there are no figured scales for the plans, which vary widely in their ratio of

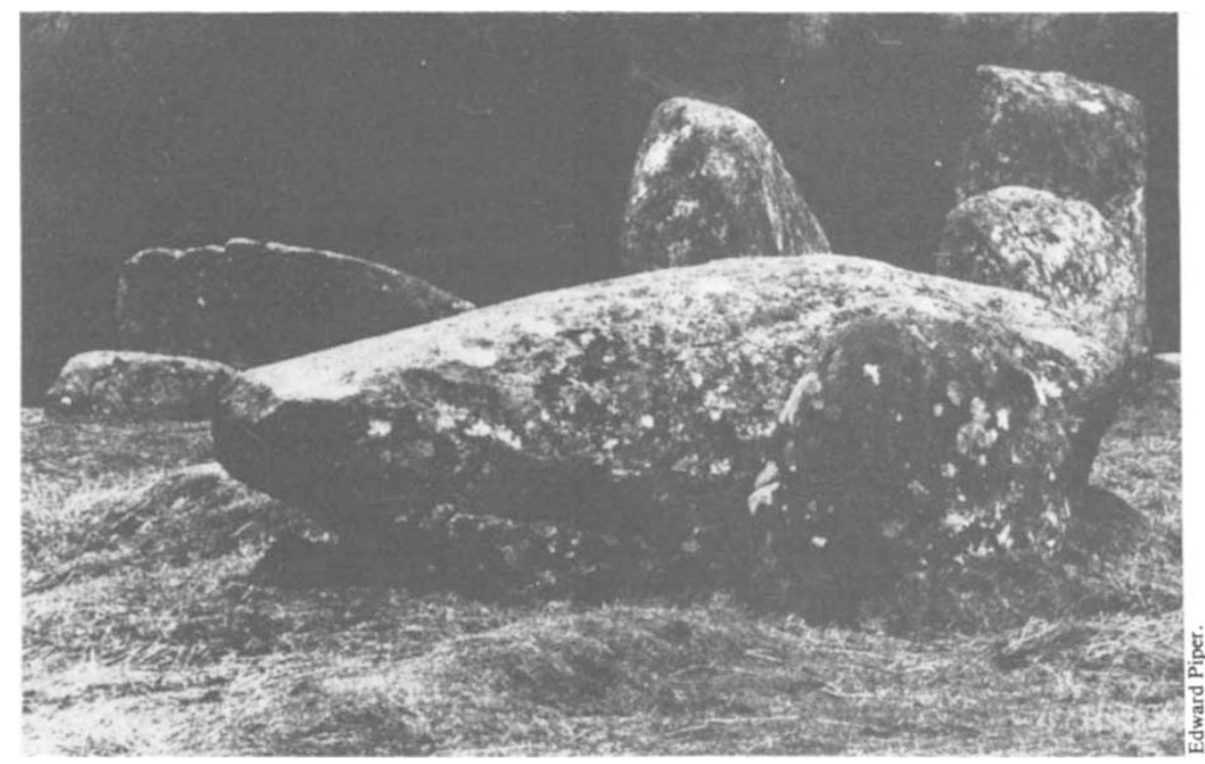

reproduction; but the principal dimensions are given in the headings.

The photographs, of which there are 106 in black-and-white as well as those in colour, are mainly the work of Edward Piper, who has inherited much of the genius of his father, the artist John Piper. Apart from one or two of the colour plates, in which the printers have achieved an overall hue which is displeasingly chlorotic, this is the finest set of pictures of prehistoric antiquities which has ever been assembled between one pair of covers. It is a picturebook in its own right, quite apart from the accompanying text, and it will stimulate the reader to see more of these sites than the photographs can show. For those who are unable, or unwilling, to venture far from the slippered comfort of their own firesides, the combination of visual and verbal description conveys very well the variety of size and character of stone circles, and readily explains their appeal to the antiquaries and topographers of the Romantic Age, which is still happily not dead.

This guide for the visitor is preceded by ten short chapters, in which Burl summarizes his unrivalled knowledge of the stone circles of the British Isles and gives his own views about their purpose and date. He begins with one of the principal regional groups, which is also morphologically and archaeologically the most coherent: the Recumbent Stone Circles of north-eastern Scotland. Here ten or eleven stones, rising in height towards a pair flanking a recumbent slab lying on edge and often with a top surface accurately horizontal, surround a low annular cairn of small boulders with a small central open space, in which excavation has frequently revealed signs of burning and small deposits of cremated human bone, accompanied significantly often by fragments of quartz.

The paucity of the human remains leads Burl to conclude, and doubtless rightly, that these were not cemeteries, but places of worship for a single extended family, sanctified at their inception by a token burial or burials, perhaps as the sequel to deliberate sacrifice. He notes, however, that although a single family could have 
raised all the upright stones, the transport of the recumbent stone (typically of 20 tonnes or more) required the combined efforts of the able-bodied members (and perhaps the males only) of a number of families. This provides a tantalizing glimpse of community action, and perhaps of a clan organization, in the late third and early second millennium $\mathrm{BC}$; but its details are beyond the limits of valid inference from the evidence.

Burl also shows, in more detail than in his earlier book, that the position of almost all the recumbent stones lies within the azimuth range of the moon at its minimum declination; and he therefore posits a symbolic link between the moon and the dead who sanctified these sites.

In the remaining hundreds of stone circles elsewhere there is little to be seen of any recurrent pattern, save that they are of stone and approximately circular. Some but not all of the few which have been comprehensively excavated have produced burials, but again of a token or dedicatory kind, or as manifestly later additions, in the Early Bronze Age, to monuments built centuries before. They vary greatly in size, from the huge ring at Avebury to tiny circles which would very nearly fit into the study in which I write this review; and in date they seem to cover a period of about two thousand years, starting around 3,500 BC. Within such wide ranges it is probably futile, as Burl implicitly recognizes, to seek any simple or universal explanation. It is better to admit, however reluctantly, that there are many interesting questions about the prehistoric past which are per se unanswerable, simply because there are no documents to give a clue to motives. Motive, except in the trivial sense of intending to do what was done, cannot be inferred from inanimate objects and structures. In answer to the question 'Why?' the evidence is dumb.

This otherwise excellent book dismisses too forthrightly the putative evidence from stone circles for the early development of scientific concepts. For Burl, the megalithic yard is "a chimaera, a grotesque statistical misconception". It is indeed a product of statistical inference; but two independent treatments of the data by different means have agreed, at the least, that further investigation is necessary
(Trans. R. Soc. Lond. A276, 1974; J. R. stat. Soc. A139, 1976).

Burl likewise implicitly rejects Thom's hypotheses about how the non-circular rings (flattened circles, eggs, compound rings) were set out, on the grounds that alternative constructions, using only pegs and a loop of measuring cord, yield an equally good fit to the stones surveyed. He may be right; but he ignores or evades the point that even if these shapes, manifestly deliberate and not accidental, are no more than the fossilized remains of games with pegs and string, they none the less constitute the foundations, gropingly laid maybe, of pure mathematics.

The astronomical aspects of stone circles can be assessed only statistically, using the largest samples available, because putatively significant alignments can obviously occur by chance. Independent checks of the claims of Thom and his followers are only now in progress. Their outcome should not be prematurely judged, in advance of publication.

R. J. C. Atkinson is Professor of Archaeology at University College, Cardiff, UK.

\section{Electronic theory of cancer}

\section{M. Coombs}

Submolecular Biology and Cancer. Ciba Foundation Symposium, No. 67. Pp. 349. (Excerpta Medica: Amsterdam, 1979.) $\$ 42.50$, Dfl.87.

THIS book reports the proceedings of the 67th Ciba Foundation symposium, held in honour of Albert Szent-Györgyi on the occasion of his 85th birthday in 1978 .

In an introduction by the Chairman ( $R$. J. P. Williams) it is noted that although "submolecular" refers to systems at a lower level than whole molecules, in the present context it is largely confined to electrons. Szent-Györgyi next outlines his views on "the living state and cancer", and the possible relationships between submolecular biology and cancer are enumerated. The greater part of the book is devoted to fifteen lectures, each with its own discussion, and ends with a general consideration of Szent-Györgyi's hypothesis.

The sharp distinction between living and inanimate matter leads Szent-Gyorgyi to conclude that a specific physical state underlies life. The subtle reactivity of living systems is thought of as an inherent property of the constituent proteins, brought about by removal of single electrons from their otherwise fully occupied orbitals. Positive electron holes thus produced lead to electrieal conductivity, with the ability of the desaturated proteins to carry information in the form of electrical signals. It is proposed that "the living state is the electronically desaturated state of molecules, and the degree of development and differentiation is a function of the degree of electronic desaturation'. When life began on Earth the atmosphere lacked molecular oxygen; electronic desaturation of proteins was accomplished by simple aldehydes, such as methylglyoxal $\left(\mathrm{CH}_{3}\right.$. CO.CHO), which are good electron acceptors. This led to a low degree of development, termed the $\alpha$-state. Later the advent of atmospheric oxygen, a much better electron acceptor, led to the highly developed $\beta$-state existing today. Here a related molecule, ascorbic acid (vitamin C), acts essentially as a catalyst for the electronic desaturation of proteins by oxygen. Cancer is thought of as a reversion to the $\alpha$-state.

It is obvious from the studies described in the subsequent chapters that little evidence can be found for electrical conductivity in proteins treated with electron acceptors, although here the virtual impossibility of making measurements on proteins in their native state may obscure true results. Nor is the anti-cancer activity of certain aldehydes apparently mediated in the way suggested by the hypothesis; moreover, it now seems very doubtful whether vitamin $C$ is useful in the clinical treatment of the disease. Furthermore, experiment does not support the idea that there are differences in free radical levels between normal and tumour

\section{IMAGE UNAVAILABLE FOR COPYRIGHT REASONS}

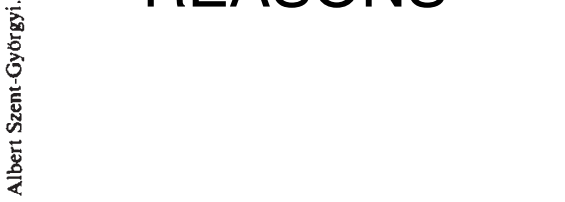

cells. However, R. Damadian, in developing the technique of whole-body nuclear magnetic resonance scanning, can distinguish normal from cancer tissue by the prolonged relaxation of protons in the latter. This indicates increased disorder in the structure of water in tumours, but just how this ties in with Szent-Gyorgyi's theory is unclear. To summarize, it is disappointing that this novel hypothesis has so far failed to find solid experimental confirmation.

The book is well produced and free from errors; its cost does not seem unreasonable in this age of unreasonable prices.

M. M. Coombs is in the Chemistry Laboratory, Imperial Cancer Research Fund, Lincoln's Inn Fields, London, UK. 